\title{
25-Hydroxycholesterol 3-Sulfate Recovers Acetaminophen Induced Acute Liver Injury via Stabilizing Mitochondria in Mouse Models
}

\author{
Yaping Wang, William M. Pandak, Edward J. Lesnefsky, Phillip B. Hylemon and Shunlin Ren * \\ Department of Internal Medicine, McGuire Veterans Affairs Medical Center, Virginia Commonwealth University, \\ Richmond, VA 23249, USA; yaping.wang@vcuhealth.org (Y.W.); william.pandak@va.gov (W.M.P.); \\ edward.lesnefsky@vcuhealth.org (E.J.L.); Phillip.Hylemon@vcuhealth.org (P.B.H.) \\ * Correspondence: shunlin.ren@vcuhealth.org; Tel.: +1-804-675-5000 (ext. 4973)
}

check for updates

Citation: Wang, Y.; Pandak, W.M.; Lesnefsky, E.J.; Hylemon, P.B.; Ren, S. 25-Hydroxycholesterol 3-Sulfate Recovers Acetaminophen Induced Acute Liver Injury via Stabilizing Mitochondria in Mouse Models. Cells 2021, 10, 3027. https://doi.org/ 10.3390/cells10113027

Academic Editors: Heather Francis and Ali Canbay

Received: 29 September 2021 Accepted: 3 November 2021 Published: 5 November 2021

Publisher's Note: MDPI stays neutral with regard to jurisdictional claims in published maps and institutional affiliations.

Copyright: (C) 2021 by the authors. Licensee MDPI, Basel, Switzerland. This article is an open access article distributed under the terms and conditions of the Creative Commons Attribution (CC BY) license (https:// creativecommons.org/licenses/by/ $4.0 /)$.
Abstract: Acetaminophen (APAP) overdose is one of the most frequent causes of acute liver failure (ALF). N-acetylcysteine (NAC) is currently being used as part of the standard care in the clinic but its usage has been limited in severe cases, in which liver transplantation becomes the only treatment option. Therefore, there still is a need for a specific and effective therapy for APAP induced ALF. In the current study, we have demonstrated that treatment with 25-Hydroxycholesterol 3-Sulfate (25HC3S) not only significantly reduced mortality but also decreased the plasma levels of liver injury markers, including LDH, AST, and ALT, in APAP overdosed mouse models. 25HC3S also decreased the expression of those genes involved in cell apoptosis, stabilized mitochondrial polarization, and significantly decreased the levels of oxidants, malondialdehyde (MDA), and reactive oxygen species (ROS). Whole genome bisulfite sequencing analysis showed that 25HC3S increased demethylation of ${ }^{5 \mathrm{~m}} \mathrm{CpG}$ in key promoter regions and thereby increased the expression of those genes involved in MAPK-ERK and PI3K-Akt signaling pathways. We concluded that 25HC3S may alleviate APAP induced liver injury via up-regulating the master signaling pathways and maintaining mitochondrial membrane polarization. The results suggest that $25 \mathrm{HC} 3 \mathrm{~S}$ treatment facilitates the recovery and significantly decreases the mortality of APAP induced acute liver injury and has a synergistic effect with NAC in propylene glycol (PG) for the injury.

Keywords: 25HC3S; oxysterol sulfation; acute liver injury; acetaminophen; DNA CpG methylation

\section{Introduction}

Acute liver failure (ALF) involves the rapid loss of liver function [1]. The clinical presentation of ALF usually includes liver dysfunction, coagulopathy, development of encephalopathy, multi organ failure, and death in over $50 \%$ of the cases [2]. Histologically, patients with ALF develop hepatic inflammation leading to fulminant hepatic necrosis and apoptosis. Causes of ALF include, but are not limited to, drug toxicity, viruses, toxins, and ischemia [3]. In the United States and Western Europe, over 50\% of all cases of ALF have been attributed to drug-induced hepatotoxicity, especially, acetaminophen (APAP, also known as paracetamol) overdose-induced ALF, which exceeds other drugs by a 4:1 ratio. However, the overall rarity of ALF has limited experimental information to guide its supportive care [4]. Although NAC has been successfully used in the clinic in some cases, liver transplantation remains the only treatment option in severe cases. Hence, there is an unmet medical need to develop an effective therapy for ALF.

APAP has widely been used to treat fever and mild to moderate pain [5]. Hepatocellular death in APAP induced ALF is the result of the formation of highly toxic intermediate $\mathrm{N}$-acetyl-p-benzoquinoneimine (NAPQI) $[6,7]$. The primary metabolic pathway for APAP is glucuronidation and sulfation, which yields relatively non-toxic metabolites that are excreted via the biliary system [8,9]. However, a small amount of the drug can be metabolized via cytochrome P-450 and yield NAPQI, which can be inactivated by conjugating 
to glutathione under normal circumstances [10]. When APAP is overdosed at toxic levels (generally $\geq 7.5 \mathrm{~g}-10 \mathrm{~g}$ in an average adult), glucuronidation and sulfation metabolic pathways are saturated and more NAPQI is produced, which may result in glutathione depletion. NAPQI results in increased mitochondrial permeability through formation of protein adducts by binding to cysteine groups on mitochondrial proteins and ion channels [11,12]. This mitochondrial stress or depolarization results in dysfunction of ATP production, imbalance of cellular ions, leakage of mitochondrial cytochrome $\mathrm{c}$ into the cytosol, and eventually cell apoptosis and necrosis [13-15].

Oxysterols are oxidized forms of cholesterol that are important in many biological processes including: cholesterol homeostasis, atherosclerosis, platelet aggregation, and apoptosis [16,17]. 25-hydroxycholesterol (25HC), an oxysterol biosynthesized from cholesterol by CYP27A1, can be sulfated by SULT2B to generate 25-hydroxycholesterol 3-sulfate (25HC3S) $[18,19]$. 25HC3S has been reported to suppress inflammatory responses, inhibit cellular apoptosis, and improve cellular survival [20-28]. As reported previously, administration of 25HC3S significantly alleviated injury in multiple organs and reduced mortality in the lipopolysaccharide (LPS)-induced endotoxin shock mouse model [29]. Recent studies have shown that $25 \mathrm{HC}$ and $25 \mathrm{HC} 3 \mathrm{~S}$ served as paired epigenetic regulators, playing an important role in global gene regulation by methylating and demethylating ${ }^{5 \mathrm{~m}} \mathrm{CpG}$ in key promoter regions involved in many cellular signaling pathways [30]. Regulation of gene expression via demethylation of ${ }^{5 \mathrm{~m}} \mathrm{CpG}$ in promoter regions may be the primary mechanism by which $25 \mathrm{HC} 3 \mathrm{~S}$ decreases lipid accumulation, reduces inflammation, and increases cell survival.

In the current study, we explored the effect of 25HC3S in the APAP-induced ALF and organ injury mouse models. The results showed that $25 \mathrm{HC} 3 \mathrm{~S}$ significantly decreased mortality, improved hepatic function, increased mitochondrial polarization, and reduced the levels of oxidants and cell death (especially apoptosis) following APAP overdose. These activities of $25 \mathrm{HC} 3 \mathrm{~S}$ appeared to be mediated by demethylation of ${ }^{5 \mathrm{~m}} \mathrm{CpG}$ in key promoter regions of genes involved in MAPK-ERK and PI3K-Akt cell signaling pathways.

\section{Materials and Methods}

\subsection{Materials}

APAP was purchased from Sigma-Aldrich (St. Louis, MO, USA). 25-Hydroxycholesterol was commercially sourced from Steraloids Inc. (Newport, RI, USA). 25HC3S was synthesized and purified in our laboratory as previously described [22]. The reagents for real-time RT-PCR were obtained from Applied Biosystems (Applied Biosystems, Foster City, CA, USA). The RT ${ }^{2}$ Profiler PCR Array-Cell Death Pathway Finder was acquired from QIAGEN (Valencia, CA, USA). MitoProbe JC-1 Assay Kit for Flow Cytometry and H2DCFDA were purchased from Life Technologies (Carlsbad, CA, USA). Propylene glycol (PG), hydroxypropyl- $\beta$-cyclodextrin (HBC), paraformaldehyde, phosphate buffer, 2-thiobarbituric acid (TBA) and malondialdehyde (MDA) were purchased from Sigma-Aldrich (St. Louis, MO, USA). Cell culture media were obtained from Invitrogen (Carlsbad, CA, USA). All other reagents were from Sigma-Aldrich unless otherwise indicated.

\subsection{Animal Studies}

Animal studies were approved by the Institutional Animal Care and Use Committee of McGuire Veterans Affairs Medical Center and were conducted in accordance with the Declaration of Helsinki, the Guide for the Care and Use of Laboratory Animals, and all applicable regulations. Two mouse models, $350 \mathrm{mg}$ and $600 \mathrm{mg} / \mathrm{kg}$ of APAP, were used: (1) To study the effect of 25HC3S on liver injury induced by APAP overdose, 12-week-old male C57BL/6J mice (Jackson Laboratory, Bar Harbor, ME, USA) were weight-pair assigned into three groups, control, vehicle, and 25HC3S groups. All mice were intraperitoneally (IP) injected with $350 \mathrm{mg} / \mathrm{kg}$ APAP (dissolved in $10 \%$ glucose/water at $14 \mathrm{mg} / \mathrm{mL}$ ) [31]. At $-2 \mathrm{~h},-1 \mathrm{~h}, 0 \mathrm{~h},+30 \mathrm{~min},+1 \mathrm{~h}$ or $+2 \mathrm{~h}$ before, on, or after challenge with APAP, the control group of mice was intravenously (IV) injected with $10 \%$ glucose in sterile water, the vehicle 
had $20 \%$ PG and $4 \% \mathrm{HBC}$ in $10 \%$ glucose/water, and the $25 \mathrm{HC} 3 \mathrm{~S}$ group had $25 \mathrm{mg} / \mathrm{kg}$ of the drug in vehicle. (2) For the mortality experiment, 12-week-old female mice were weight-pair assigned into three groups with each receiving IV injection of control, vehicle, or $25 \mathrm{HC} 3 \mathrm{~S}(25 \mathrm{mg} / \mathrm{kg}) 2 \mathrm{~h}$ before IP injection of $600 \mathrm{mg} / \mathrm{kg}$ APAP in sterile $10 \%$ glucose water. All mice were housed under identical conditions in an aseptic facility with a 12-h light/12-h dark cycle and given free access to water and food. Blood and tissue samples were collected at $24 \mathrm{~h}$ after APAP injection under anesthesia. Serum enzymatic activities of alkaline phosphatase (ALK), alanine aminotransferase (ALT), aspartate aminotransferase (AST), and lactate dehydrogenase (LDH) were measured in the clinical laboratory at McGuire Veterans Affairs Medical Center. Mouse survival was monitored every $2 \mathrm{~h}$ during the daytime and $12 \mathrm{~h}$ during the night.

\subsection{Histological Analysis}

Three specimens from different regions of the liver/lung/kidney of each mouse were collected and fixed in 10\% paraformaldehyde in $0.1 \mathrm{M}$ phosphate buffer at room temperature overnight. The regions of the specimens were standardized for all mice. The paraffin-embedded tissue sections $(4 \mu \mathrm{m})$ were prepared by the Department of Pathology, School of Medicine, Virginia Commonwealth University, then deparaffinized and stained using a standard hematoxylin and eosin (H\&E) method [29].

Ten images per sample were taken at $\times 400$ magnification by light microscope and scored by two pathologists in a blinded manner. The severity of microscopic lung injury was graded from 0 (normal) to 3 (severe) based on the degree or amount of (a) congestion of alveolar septae; (b) alveolar hemorrhage; (c) intra-alveolar fibrin; (d) intra-alveolar infiltrates. The total injury score made up of four components was computed for each mouse. The degree of liver injury was determined by the percentage of hepatic parenchyma with apoptosis/necrosis or inflammation and graded on a sliding scale of: 0 , absent; 0.5 , minimal; 1 , mild; 1.5 , mild-to-moderate; 2, moderate; 2.5, moderate-to-marked; and 3, marked [32]. Renal tubular injury was assessed using a score in which the percentage of cortical tubules showing epithelial necrosis was assigned a score of either 0 , none; $1,<10 \%$; $2,10-25 \% ; 3,25-75 \%$; or $4,>75 \%$ [29].

\subsection{Quantitative Real-Time Polymerase Chain Reaction ( $q$ RT-PCR) Analysis}

The relative mRNA levels were measured by real-time reverse transcriptase polymerase chain reaction as previously described [29]. Briefly, total RNA was isolated with an SV Total RNA Isolation Kit (Promega, Madison, WI, USA) that included DNase I treatment. About $2 \mu \mathrm{g}$ total RNA was used in the first-strand cDNA synthesis as recommended by the manufacturer (Invitrogen, Carlsbad, CA, USA). Quantitative RT-PCR was performed using SYBR Green as an indicator in an ABI 7500 Fast Real-Time PCR System (Applied Biosystems, Foster City, CA, USA). The amplification of Rn18s was used as an internal control. The sequences of primers were designed as recommended by the https://pga.mgh.harvard.edu/primerbank/ (accssed on 17 August 2020) and are summarized in Supplementary Materials Table S1.

\section{5. $R T^{2}$ Profiler PCR Array (Cell Death Pathway Finder) Analysis}

Cell death is the major cause of organ injury during the process of endotoxin shock. The mouse Cell Death Pathway Finder RT $^{2}$ Profiler PCR Array was used in the present study to identify the changes in expression of genes involved in the cell death pathways. This PCR array was to detect the 84 key gene expression (mRNA levels), which are involved in central mechanisms of cellular death including apoptosis, autophagy, and necrosis. Twenty-four hours after overdose with APAP (with or without PG or 25HC3S), liver tissues were collected from the mice, and total RNA was isolated from $0.1 \mathrm{~g}$ tissue as described previously [29]. After reverse transcription into first-strand cDNA with the $\mathrm{RT}^{2}$ First Strand Kit (QIAGEN, Hilden, Germany), all samples were subjected to the $\mathrm{RT}^{2}$ Profiler PCR Array Cell Death Pathway Finder assay following the manufacturer's instructions. The Qiagen 
PCR Array Data Analysis complementary web-based software was used for analysis and interpreting array data.

\subsection{Analysis of Whole Genome Bisulfite Sequencing (WGBS)}

Genomic DNAs were extracted from $25 \mathrm{mg}$ liver tissues, which were collected from normal, vehicle, or 25HC3S treated mice using QIAamp DNA Mini Kit (QIAGEN, Hilden, Germany). Each sample, $6 \mu \mathrm{g}$, was sent to Novogene Co., Ltd. (Tianjin, China) for analysis of whole genome bisulfite sequencing (WGBS). Each sample, $5.2 \mathrm{~g}$ of genomic DNA spiked with $26 \mathrm{ng}$ lambda DNA was fragmented by sonication to 200-300 bp with Covaris S220, followed by end repair and adenylation. Cytosine-methylated barcodes were ligated to sonicated DNA as manufacturer's instructions. These DNA fragments were treated twice with bisulfate using EZ DNA Methylation-Gold TM Kit (Zymo Research, Irvine, CA, USA) before the resulting single-strand DNA fragments were PCR amplified using KAPA HiFi Hot Start Uracil and Ready Mix $(2 \times)$. Library concentration was quantified by Qubit ${ }^{\circledR} 2.0$ Fluorometer (Life Technologies, Carlsbad, CA, USA) and quantitative PCR, and the insert size was assayed using an Agilent Bioanalyzer 2100 system.

The library preparations were sequenced using an Illumina Hiseq 2500/4000 or Novaseq platform and $125 \mathrm{bp} / 150 \mathrm{bp}$ paired-end reads were generated. Image analysis and base calling were performed with Illumina CASAVA pipeline, and finally $125 \mathrm{bp} / 150 \mathrm{bp}$ paired-end reads were generated. Trimmomatic (v0.36) software was used for quality control. Bismark software (version 0.16.3; Krueger F, 2011) was used to perform alignments of bisulfite-treated reads to a reference genome (X 700-dovetail). DSS software (DSS 2.34.0) was used to identify differentially methylated regions (DMRs). KOBAS software (KOBAS 2.0)was used to test the statistical enrichment of DMR related genes in the Kyoto Encyclopedia of Genes and Genomes (KEGG) pathways [33].

\subsection{Analysis of Mitochondrial Potential}

Changes in mitochondrial membrane potential (MMP) were measured using the MitoProbe JC-1 assay kit for flow cytometry (Invitrogen, Carlsbad, CA, USA). The Huh-7 cell line was routinely grown in DMEM containing 10\% fetal bovine serum (FBS), $100 \mathrm{IU} / \mathrm{mL}$ penicillin, and $100 \mathrm{mg} / \mathrm{mL}$ streptomycin and incubated at $37{ }^{\circ} \mathrm{C}$ in a $0.5 \% \mathrm{CO}_{2}$ incubator. For the MMP experiment, Huh-7 cells were first seeded at a density of $6.5 \times 10^{5}$ per dish in $60 \mathrm{~mm}$ dishes. Twenty-four hours after seeding, cells were pretreated with the indicated concentrations of 25HC3S and/or vehicle for $2 \mathrm{~h}$ before $10 \mathrm{mM}$ APAP was added [34]. Twenty-four hours after APAP addition, media were removed, and the cells were trypsinized and resuspended in PBS (Invitrogen, Carlsbad, CA, USA). Mitochondria were stained by JC-1 according to the manufacturer's instructions, and the fluorescence was detected and measured by fluorescence-activated cell sorting (Virginia Commonwealth University FACS Shared Core).

\subsection{Measurement of Intracellular ROS}

The amount of intracellular reactive oxygen species (ROS) in vitro was measured using H2DCFDA ( $2^{\prime}, 7^{\prime}$-Dichlorodihydro fluorescein diacetate) as an indicator for ROS in cells [35]. Huh-7 cells were routinely grown in DMEM containing 10\% FBS, $100 \mathrm{IU} / \mathrm{mL}$ penicillin, and $100 \mathrm{mg} / \mathrm{mL}$ streptomycin and incubated at $37^{\circ} \mathrm{C}$ in a $0.5 \% \mathrm{CO}_{2}$ incubator. For the ROS detection, Huh-7 cells were first seeded at a density of $6.5 \times 10^{5}$ per dish in $60 \mathrm{~mm}$ dishes. Twenty-four hours after seeding, cells were pretreated with $50 \mu \mathrm{M} 25 \mathrm{HC} 3 \mathrm{~S}$ and/or vehicle for $2 \mathrm{~h}$ before $10 \mathrm{mM}$ APAP was added. Sixteen hours after APAP addition, media were removed, and the cells were trypsinized and resuspended in PBS. H2DCFDA was then added to the suspended cells at a final concentration of $10 \mu \mathrm{M}$ in the dark in an incubator for $30 \mathrm{~min}$ and immediately used for ROS detection by flow cytometry at an excitation/emission wavelength of $485 / 530 \mathrm{~nm}$. Results were also expressed as the percentage increased relative to untreated cells. 


\subsection{Hepatic Lipid Peroxidation (Malondialdehyde, MDA) Assay}

Lipid peroxidation of liver in mice was evaluated by measuring the thiobarbituric acid (TBA) according to the modified method by Ohkawa and Mihara [36,37]. Briefly, liver tissue ( 100 mg) was homogenized in $1 \mathrm{~mL}$ PBS containing $1 \mathrm{mM}$ EDTA and centrifuged at $500 \times \mathrm{g}$ for $10 \mathrm{~min}$ at $4{ }^{\circ} \mathrm{C}$. To each $0.5 \mathrm{~mL}$ of $10 \%$ homogenate of the tissue sample, add $3 \mathrm{~mL}$ of $1 \% \mathrm{H}_{3} \mathrm{PO}_{4}$ and $1 \mathrm{~mL}$ of $0.6 \%$ TBA aqueous solution: stir and heat the mixture on a boiling water bath for $45 \mathrm{~min}$. After cooling, add $4 \mathrm{~mL}$ of $n$-butanol, shake, and separate the butanol layer by centrifugation; determine the optical density of the butanol layer at 535 and $520 \mathrm{~nm}$; calculate the difference of optical density between the two determinations to be taken as the TBA value. MDA levels were normalized to the hepatic cell protein content as determined by the bicinchoninic acid assay kit purchased from Pierce (Rockford, IL, USA). The amount of lipid peroxidation was expressed as $\mathrm{nmol} / \mathrm{mg}$ protein.

\subsection{Statistical Analysis}

Data were reported as the mean \pm standard deviation (S.D.) and subjected to one-way ANOVA with posthoc Tukey analysis (for multiple groups comparisons and normal distribution). An F test or the Student-Neuman-Keuls post-hoc test analyses were performed on these data to analyze the variances and significances between groups (for two group comparison, two-sided). The Kaplan-Meier Log-Rank test was used for survival analysis. All analyses were performed with SPSS software version 19 for Macintosh. Statistical significance was defined as $p<0.05$.

\section{Results}

\subsection{HC3S Alleviates Injured Liver Function and Increases Survival Rates in APAP Mouse Model}

In order to determine the effect of $25 \mathrm{HC} 3 \mathrm{~S}$ on liver injury in APAP challenged mice, 12week-old male C57BL/6J mice were weight-pair assigned into three groups, the control, the vehicle, and the 25HC3S. To avoid the liver damage caused by starving, $10 \%$ glucose was used in APAP solution, which gave more consistent results (data not shown), indicating this is a better model. For the mortality experiment, each group of mice was treated with control (10\% glucose), the vehicle (or PG), or $25 \mathrm{HC} 3 \mathrm{~S}(25 \mathrm{mg} / \mathrm{kg}$ ) by IV injection $2 \mathrm{~h}$ before IP injection with $600 \mathrm{mg} / \mathrm{kg}$ APAP. A global examination of liver tissues showed that APAP induced tissue injury while 25HC3S minimized it (Figure 1A). In 25HC3S pre-treated mice, the survival rate and survival interval were significantly higher than that of both the control and the PG groups ( $p$ values were 0.0174 and 0.025 , respectively). However, post-treatment showed slight decreases in the rate of mortality but not a significant difference between $25 \mathrm{HC} 3 \mathrm{~S}$ and other groups (data not shown). Interestingly, the survival rate and survival interval of the PG (vehicle) group were also higher than those in the control group ( $p$ value was 0.05 ) although was much lower than the $25 \mathrm{HC} 3 \mathrm{~S}$ group (Figure 1B). For studies of effects on the liver injury, 3 groups of mice were treated with control $(n=14)$, vehicle, or $25 \mathrm{mg} / \mathrm{kg} 25 \mathrm{HC} 3 \mathrm{~S}$ in vehicle $-2 \mathrm{~h},-1 \mathrm{~h}, 0 \mathrm{~h}, 30 \mathrm{~min},+1 \mathrm{~h}$ and $+2 \mathrm{~h}$ before, on, and after IP injection of $350 \mathrm{mg} / \mathrm{kg}$ APAP. Serum enzymatic activities of ALK, AST, and LDH were measured at $24 \mathrm{~h}$ after APAP injection. The earlier treatment, the lower levels of the serum markers are observed (data not shown). For clinical usage, the later treatment after the challenge of APAP will be more significant. The best latest treatment is the administration of $25 \mathrm{HC} 3 \mathrm{~S}$ at $30 \mathrm{~min}$ after APAP as shown in Figure 1C-E. Compared to the control group, both PG and 25HC3S treatment significantly reduced serum levels of ALT, AST and LDH by Kruskal-Wallis statistic test. Compared to the vehicle group, 25HC3S treatment had lower but not statistically significant levels of serum ALT, AST and LDH ( $p$ values are $0.0706,0.1239$ and 0.1410 , respectively). The results showed that both PG and 25HC3S alleviated liver injury or improved hepatic function at the lower dose of APAP challenge, but 25HC3S in PG provided a better outcome and with significantly decreased mortality at the higher dose. 
A
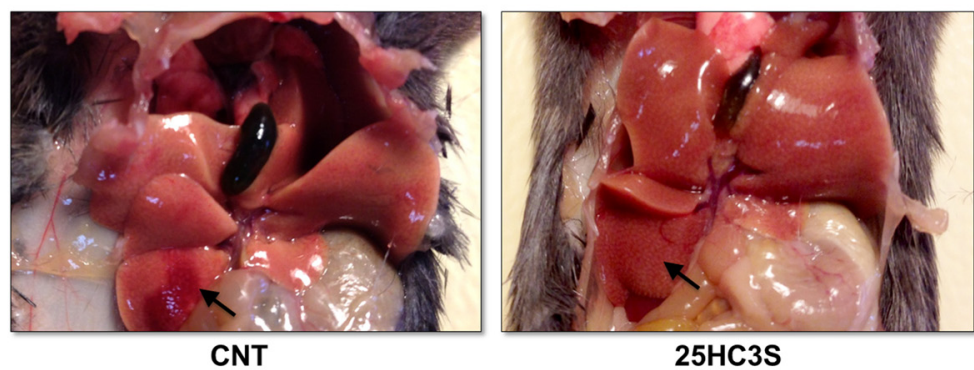

25HC3S

B

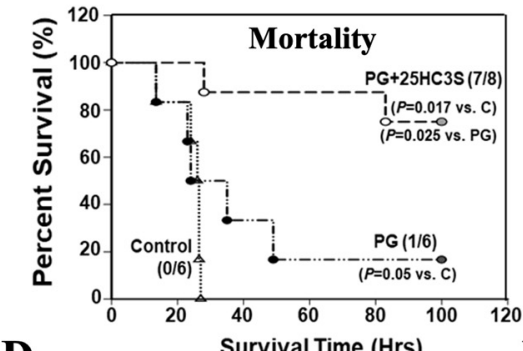

D

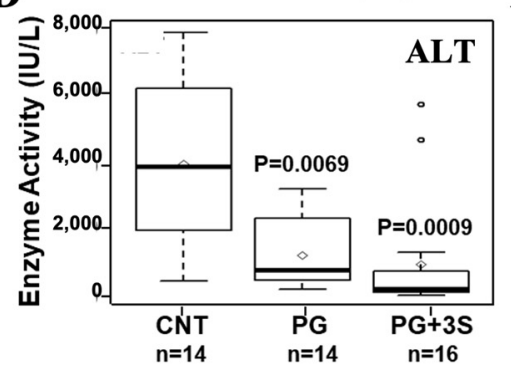

C
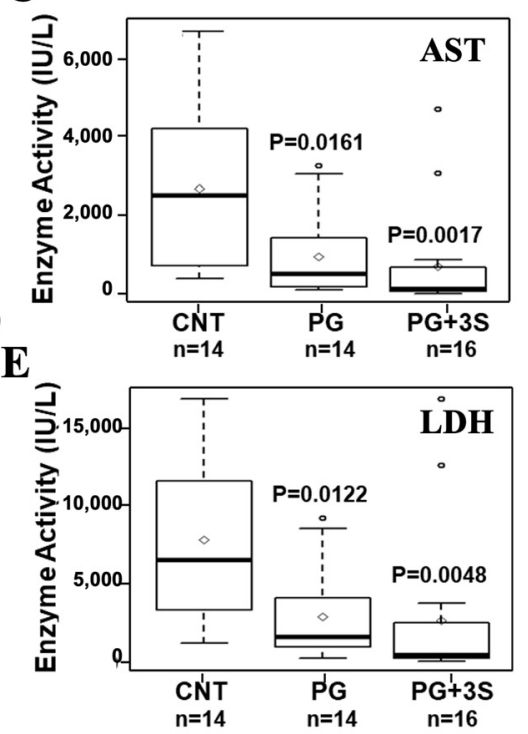

$\mathbf{F}$

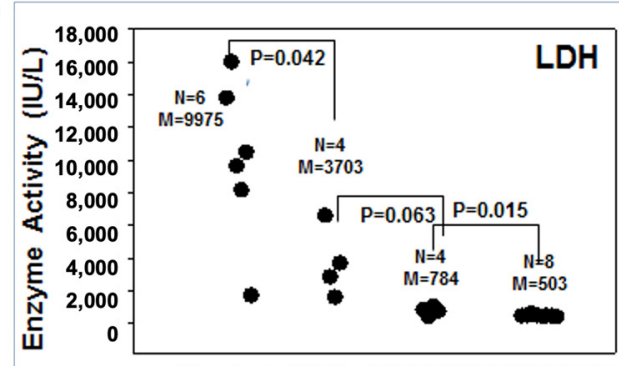

Control NAC NAC/PGNAC/3S/PG
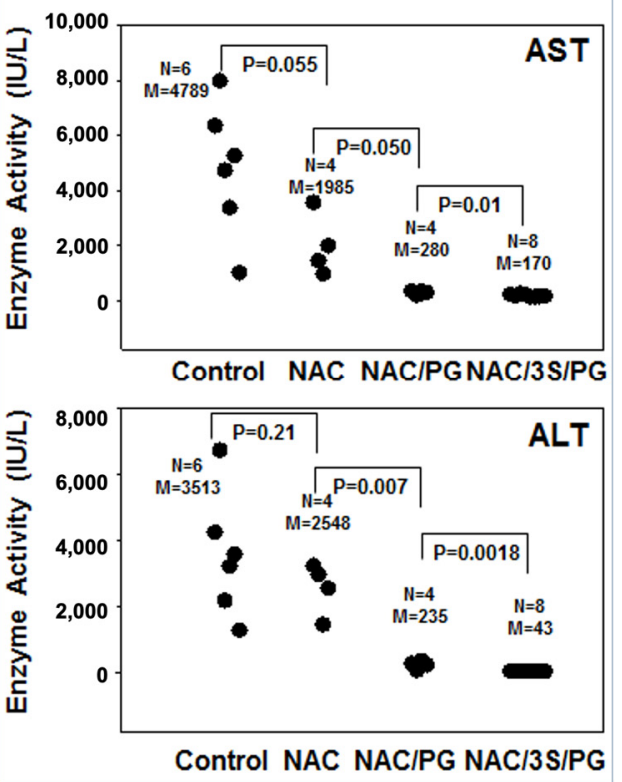

Figure 1. 25HC3S treatment improves organ function and survival rates in APAP overdose mice. 12-week-old female C57BL/6J mice were administered either with control $(n=6)$, vehicle $(n=6)$ or $25 \mathrm{HC} 3 \mathrm{~S}(n=8) 2 \mathrm{~h}$ before APAP $(600 \mathrm{mg} / \mathrm{kg})$ treatment. (A) The gross observation of liver after treated with $25 \mathrm{HC} 3 \mathrm{~S}$ in mice. The arrow indicates the site of APAP induced liver injury. (B) Mouse survival rates was observed and recorded up to $100 \mathrm{~h}$. (C-E) The mice were injected with $350 \mathrm{mg} / \mathrm{kg}$ APAP and after half hour mice were intravenously treated with $10 \%$ glucose in sterile water for the control group, vehicle (20\% propylene glycol (PG), $4 \%$ hydroxypropyl- $\beta$-cyclodextrin (HBC) in $10 \%$ glucose/water) for the PG group, and $25 \mathrm{mg} / \mathrm{kg} 25 \mathrm{HC} 3 \mathrm{~S}$ in vehicle for the $25 \mathrm{HC} 3 \mathrm{~S}$ group, respectively. After $24 \mathrm{~h}$, serum activities of AST, ALT, and LDH were determined by a clinical laboratory. CNT: represents control mice with APAP injection only; PG: represents vehicle with PG treated control mice; 3S: 25HC3S treated mice. Solid bar shows the average value of each group. (F) Effects of PG, 25HC3S in PG, NAC, NAC in PG, and NAC+25HC3S in PG on injured liver function using the models as shown in (C-E). Each point represents an individual mouse and data are pooled from three independent experiments.

NAC is currently used as part of the standard of care in APAP overdose [38]. The effect of $\mathrm{N}$-acetylcysteine and propylene glycol (NAC+PG) with or without 25HC3S on the recovery of hepatic function following APAP overdose were compared. As shown in Figure 1F, NAC+PG decreased serum levels of LDH, AST, and ALT after APAP overdose with $p$ values of $0.04,0.05$, and 0.2 , respectively. NAC alone (without PG) also reduced these liver enzymes but not statistically significant in LDH while more so in ALT ( $p$ values of $0.06,0.05$, and 0.007 , respectively). The addition of $25 \mathrm{HC} 3 \mathrm{~S}$ to NAC+PG virtually restored LDH, AST, and ALT to the normal levels with $p$ values of $0.015,0.01$, and 0.002 , respectively (Figure $1 \mathrm{~F}$ ), indicating that the combination has potential as an optimal therapy of APAP induced acute liver injury.

To confirm the effect of PG and 25HC3S+PG on the recovery of damaged tissues in APAP overdosed mice, tissues of the liver, lung, and kidney were examined by histopathology. All the tissues were severely damaged following the administration of APAP $(600 \mathrm{mg} / \mathrm{kg})$, demonstrated by overt infiltration of neutrophils, marked cellular necrosis, and profound 
structural destruction (Figure 2A), consistent with published results [39,40]. Compared to the control group, the tissue injury scores in groups pretreated with PG or 25HC3S+PG were significantly reduced. Furthermore, the tissues from the 25HC3S+PG group showed normal-like tissue structures and had much lower tissue injury scores, demonstrating that 25HC3S prevented tissue injury in APAP overdosed mice (Figure 2A,B).

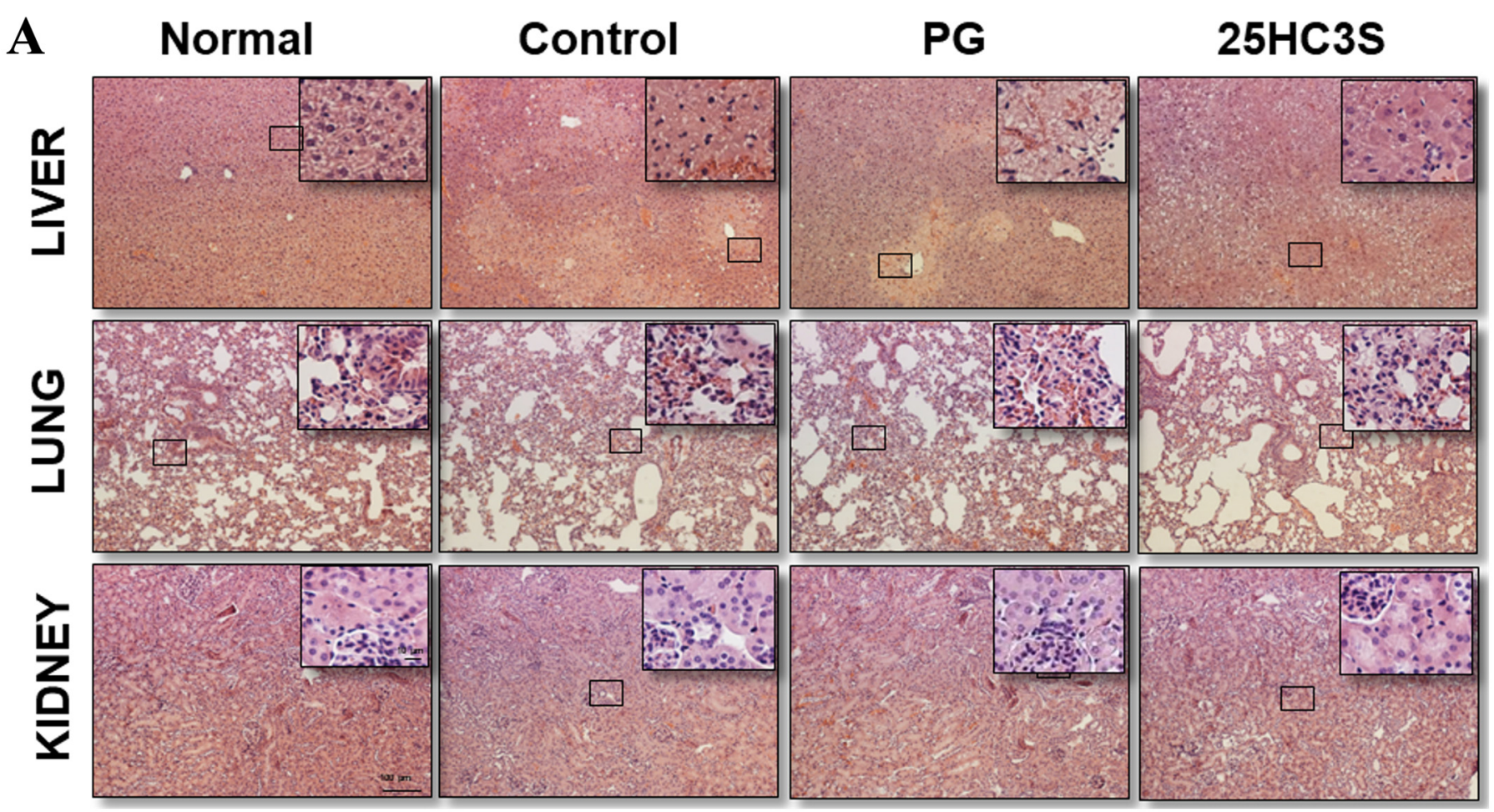

B

Score of tissue injury in different groups after APAP administration

\begin{tabular}{lllll}
\hline & Normal & Control & PG & PG+25HC3S \\
\hline Liver & 0 & $2.95 \pm 0.53$ & $2.32 \pm 0.45$ & $1.03 \pm 0.38^{* *} \dagger$ \\
Lung & $0.98 \pm 0.22$ & $6.46 \pm 0.34$ & $4.92 \pm 0.288^{* *}$ & $2.05 \pm 0.36^{* *}+\dagger$ \\
Kidney & 0 & $3.14 \pm 0.28$ & $2.53 \pm 0.31^{*}$ & $1.48 \pm 0.43^{* *} \dagger$ \\
\hline
\end{tabular}

Figure 2. Morphological study of liver, lung, and kidney tissues. 12-week-old female C57BL/6J mice were administered either with control, vehicle or $25 \mathrm{HC} 3 \mathrm{~S}$ at $2 \mathrm{~h}$ before APAP $(600 \mathrm{mg} / \mathrm{kg})$ treatment $(n=4$ for each group). The liver, lung, and kidney tissues were harvested at $24 \mathrm{~h}$ or at dying following the injection of APAP for morphological study. Tissues from age-matched mouse without any treatment were used as normal control. (A) The paraffin-embedded tissue sections were stained using H\&E method and photographed for evaluation. Representative photos are shown at $\times 100$ magnification (bar $=100 \mu \mathrm{m}$ ). Inserts are shown at $\times 400$ magnification of the boxed areas (bar $=10 \mu \mathrm{m})$. Normal represents normal mice without any treatment $(n=4)$; Control, PG vehicle-treated mice; 25HC3S, 25HC3S-pretreated mice. (B) Ten images per sample were taken at $\times 400$ magnification by light microscope and scored by two pathologists in a blinded manner. The severity of microscopic tissue injury was graded as indicated. Normal: normal mice without treatment; Control: mice with PG vehicle and APAP injection; 25HC3S: mice with 25HC3S and LPS injection $(n=4)$. The symbol * indicates $p<0.05$ and ** indicates $p<0.01$ versus Control group; + indicates $p<0.05$ and ++ indicates $p<0.01$ versus PG group. 


\subsection{HC3S Suppresses Apoptosis-Related Gene Expression in the APAP Induced Liver Injury}

To better understand the underlying mechanism behind the effects of PG and 25HC3S on APAP toxicity, an $\mathrm{RT}^{2}$ Profiler PCR Array of Mouse Cell Death Pathway was used to study the gene expression profile involved in cell apoptosis, necrosis, and autophagy. The expression of 84 genes involved in cell death in the liver was examined (Figure 3). Based on similarity of gene expression, clustergram analysis showed that the expression patterns between vehicle treated and control mice (APAP only) were similar but significantly different from those of normal mice (Figure $3 \mathrm{~A}$, lanes $\mathrm{P}$ and $\mathrm{C}$ vs. N). Interestingly, the patterns from the liver of $25 \mathrm{HC} 3 \mathrm{~S}$ treated mice were similar to normal mice but significantly different from those of control mice or vehicle (PG) mice (Figure $3 \mathrm{~A}$ lanes $\mathrm{P}+\mathrm{S}$ vs. N). Compared to the control group, scatter plot analysis showed that PG treatment both increased and decreased the expression of only one gene (Figure 3B), however, 25HC3S increased the expression of 4 genes and decreased that of 16 genes (Figure 3C). Compared to the PG group, $25 \mathrm{HC} 3 \mathrm{~S}$ treatment increased the expression of 2 and decreased 10 genes ( $>2$-fold) (Figure 3D). The detailed results are summarized in Table S2. The array results were confirmed by qRT-PCR as shown in Figure 3E. The expression of pro-inflammatory cytokine genes was determined by qRT-PCR analysis, as shown in Figure 3F. 25HC3S significantly decreased the expression of NFkB and IL-1, consistent with previous reports [21,24], as well as those genes involved in pro-apoptosis or inflammation. Meanwhile, 25HC3S increased the expression of genes involved in cell survival (anti-apoptosis) or autophagy. These results indicated that $25 \mathrm{HC} 3 \mathrm{~S}$ prevented APAP-induced cell death through the different pathway(s) or mechanisms from that of PG.

\section{3. $25 H C 3 S$ Increases Anti-Apoptosis Gene Expression via DNA ${ }^{5 m} C p G$ Demethylation}

To understand the possible function of cytosine methylation in 25HC3S treated APAP mice, the genomic DNA from the liver tissues were extracted for the construction of bisulfite-treated genomic DNA libraries. In these two libraries, more than $77 \%$ of cytosine residues were covered by at least ten reads in "GRCm38". The depth and density of the sequencing were enough for a high-quality genome-wide methylation analysis. Meanwhile, the efficiencies of bisulfite conversion, represented by the lambda DNA to the libraries, were over 99\%, providing reliable and accurate results for the WGBS (Table S2).

A total 2911 differential methylated regions (DMRs) under CG context were identified as hypomethylated regions located in 939 genes (differential methylated genes, DMGs), among which $44 \%$ (414) of the DMGs were identified in their promoters (Figure $4 \mathrm{~A}$ ) following $25 \mathrm{HC} 3 \mathrm{~S}$ treatment. The hypomethylated genes were highly enriched in 55 KEGG pathways $(p<0.05)$ (Table S3). The top 22 pathways $(p<0.02)$ were shown in Figure 4B. While no hypermethylated genes were significantly enriched into any of KEGG pathways. Among these pathways, PI3K-Akt and MAPK signaling pathways are believed to be the master pathways regulating cell proliferation and cell death. The chromosome and sequence location of the hypomethylated $\mathrm{CpG}$ by $25 \mathrm{HC} 3 \mathrm{~S}$ in promoter regions of the key genes involved in PI3K-Akt and MAPK signaling pathway are summarized in Tables 1 and 2, respectively. The results suggest that the effects of 25HC3S on the APAP induced hepatic injury are most likely mediated by demethylation of ${ }^{5 \mathrm{~m}} \mathrm{CpG}$ in promoter regions of the key genes, such as the Fgf11, Pik3cb, Pdgfa, Pdgfb involved in PI3K-Akt and MAPK signaling pathways.

Table 1. Methylation of DMR in gene promoter regions of PI3K-AKt signaling pathway.

\begin{tabular}{cccccccc}
\hline \multirow{2}{*}{ Gene Name } & \multirow{2}{*}{ Gene Accession ID } & \multicolumn{2}{c}{ DMR Location in Promoter Region } & \multicolumn{3}{c}{ DMR (Methylation \%) } \\
\cline { 3 - 8 } & & Chromosome & Start & End & Vehicle & 25HC3S & 25HC3S-Vehicle \\
\hline F $g f 11$ & NM_010198 & Chr11 & $69,802,413$ & $69,802,474$ & 55.0 & 22.6 & -32.4 \\
Pik3cb & NM_029094 & Chr9 & $99,140,132$ & $99,140,237$ & 18.2 & 5.1 & -13.1 \\
Gm26577 & AC_153914 & Chr10 & $21,145,028$ & $21,145,169$ & 27.9 & 5.9 & -22.0 \\
Mapk1 & NM_001038663 & Chr16 & $16,983,558$ & $16,983,663$ & 11.5 & 4.8 & -6.7 \\
\hline
\end{tabular}


Table 1. Cont.

\begin{tabular}{cccccccc}
\hline \multirow{2}{*}{ Gene Name } & \multirow{2}{*}{ Gene Accession ID } & \multicolumn{3}{c}{ DMR Location in Promoter Region } & \multicolumn{3}{c}{ DMR (Methylation \%) } \\
\cline { 3 - 8 } & & Chromosome & Start & End & Vehicle & 25HC3S & 25HC3S-Vehicle \\
\hline Pdgfa & NM_008808 & Chr5 & $139,000,000$ & $139,000,000$ & 28.2 & 5.3 & -22.9 \\
Pdgfb & NM_011057 & Chr15 & $80,013,952$ & $80,014,060$ & 37.0 & 6.9 & -30.1 \\
Ppp2r5c & NM_001081458 & Chr12 & $110,000,000$ & $110,000,000$ & 47.0 & 6.6 & -40.4 \\
Ccne2 & NM_009830 & Chr4 & $11,191,626$ & $11,191,706$ & 25.6 & 7.7 & -17.9 \\
Il3ra & NM_008369 & Chr14 & $14,346,685$ & $14,346,808$ & 32.2 & 17.1 & -15.1 \\
Ywhaz & NM_001253806 & Chr15 & $36,793,096$ & $36,793,150$ & 43.7 & 7.3 & -36.4 \\
Gsk3b & NM_019827 & Chr16 & $38,089,505$ & $38,089,575$ & 23.0 & 5.5 & -17.5 \\
Tlr4 & NM_021297 & Chr4 & $66,827,577$ & $66,827,646$ & 63.5 & 25.6 & -37.9 \\
\hline
\end{tabular}

A

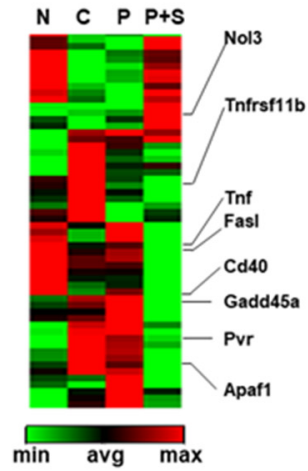

C

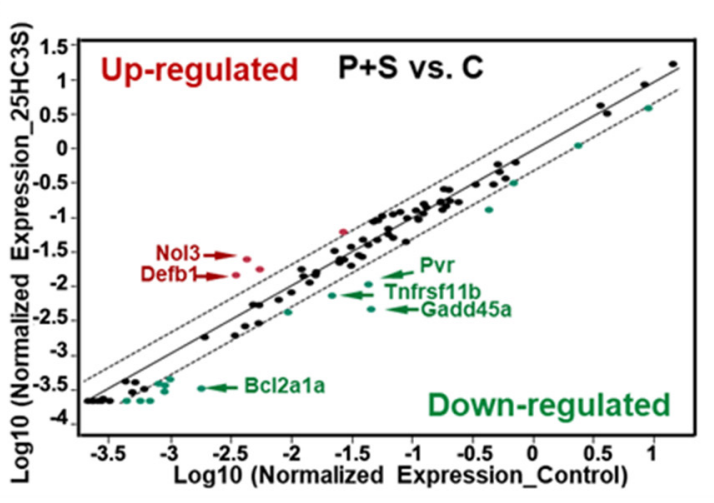

E

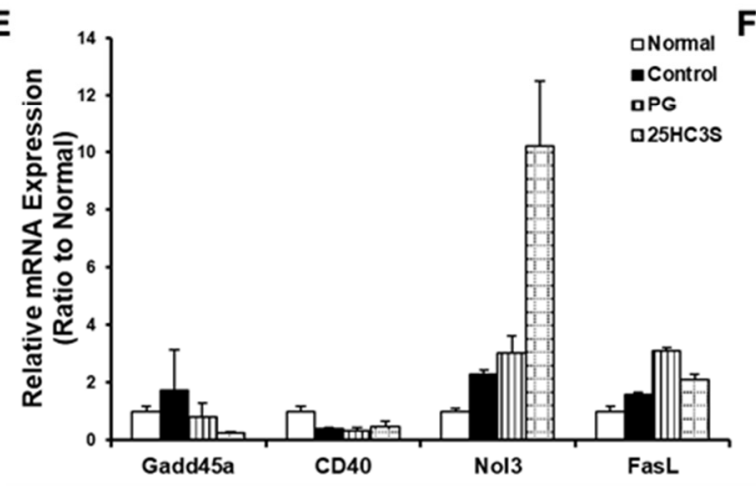

B

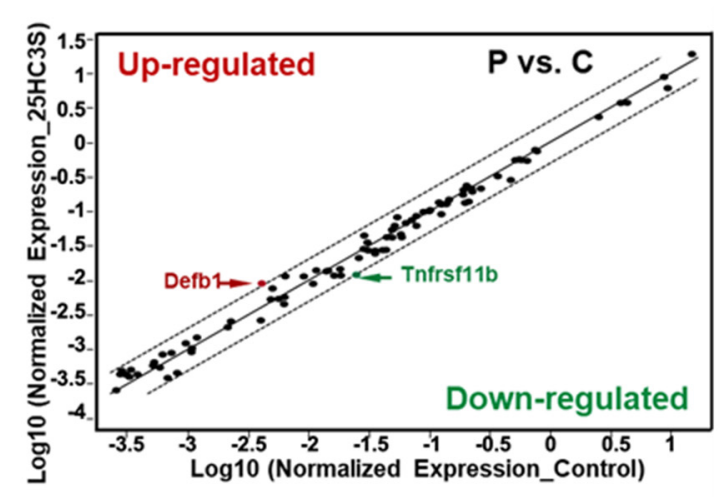

D

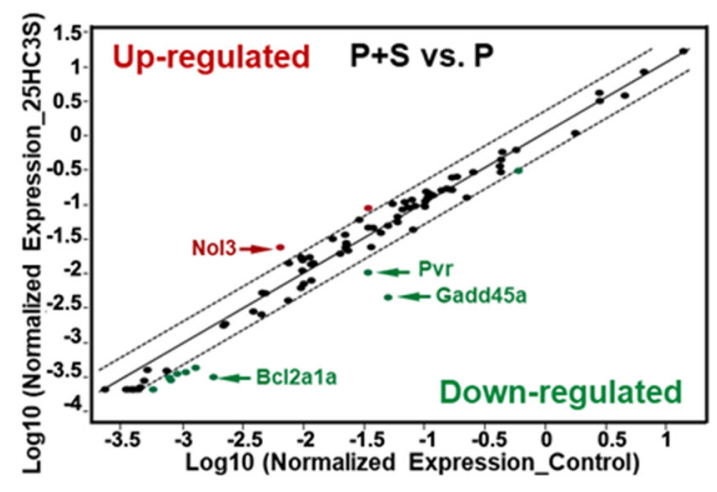

$F$

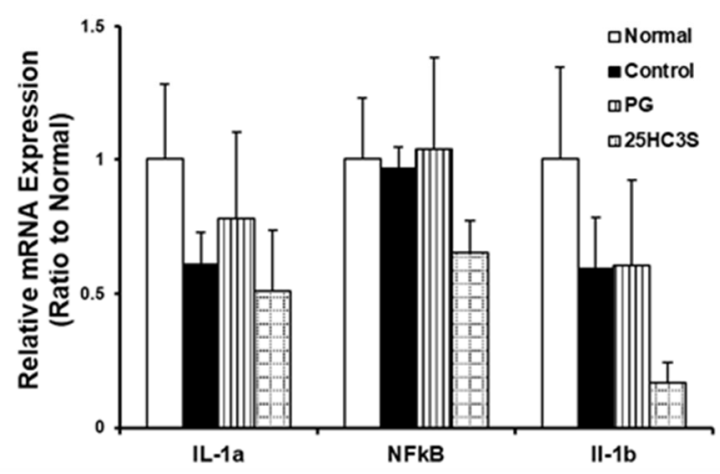

Figure 3. $25 \mathrm{HC} 3 \mathrm{~S}$ treatment regulates expression of apoptosis-related genes in the liver tissues of APAP overdose mice. 12-week-old male C57BL/6J mice were intraperitoneally injected with $350 \mathrm{mg} / \mathrm{kg}$ APAP, half an hour later, mice were intravenously injected with $10 \%$ glucose in sterile water for the control group, vehicle ( $20 \%$ propylene glycol, $4 \%$ hydroxypropyl$\beta$-cyclodextrin (HBC) in 10\% glucose/water) for the PG group, and $25 \mathrm{mg} / \mathrm{kg} 25 \mathrm{HC} 3 \mathrm{~S}$ in vehicle for the $25 \mathrm{HC} 3 \mathrm{~S}$ group respectively. Mice without any treatment were used as a normal control. Each group contained four mice. Twenty-four hours following APAP injection, liver tissues were harvested, total mRNAs were extracted, four samples from each group 
were combined, and gene expressions were determined by the $\mathrm{RT}^{2}$ Profiler PCR Array assay. (A) Clustergram analysis of gene expression profiles: Lane $\mathrm{N}$ represents normal mice without any injection; Lane C, control mice with only APAP injection; Lane P, vehicle with PG pretreated; Lane S, 25HC3S-pretreated mice. (B) (PG vs. Control), (C) (25HC3S vs. Control), and (D) (25HC3S vs. PG) show results of scatter plot analysis: gene expressions with a greater than 2-fold change are highlighted. (E) qRT-PCR analysis to confirm the results of RT $^{2}$ Profiler PCR Array assay. (F) qRT-PCR analysis to determine the expression of inflammation related genes.

A
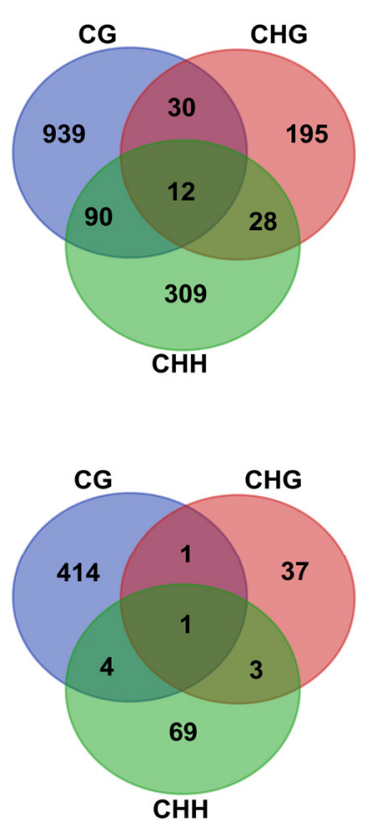

B

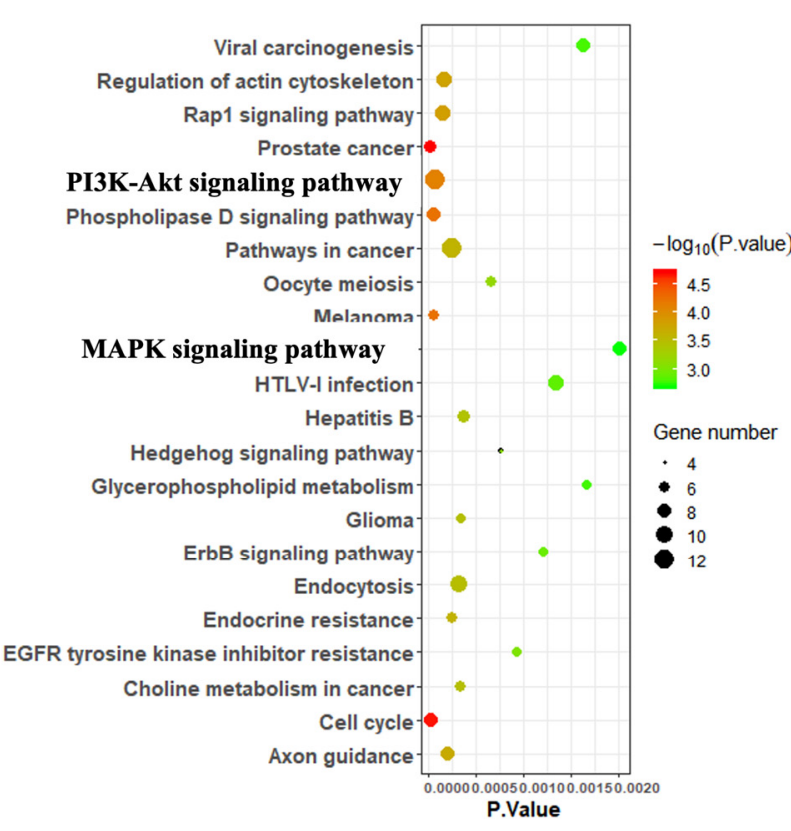

C
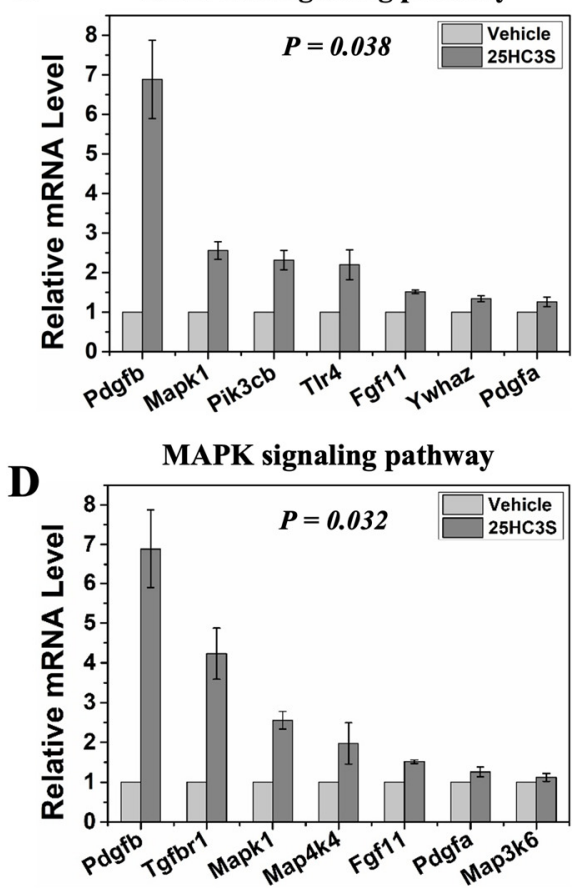

Figure 4. Effects of $25 \mathrm{HC} 3 \mathrm{~S}$ on DNA methylation in APAP induced liver injury mouse model by global methylation sequencing analysis. 12-week-old male C57BL/6J mice were intraperitoneally injected with $350 \mathrm{mg} / \mathrm{kg}$ APAP, half an hour later, mice were intravenously injected with $20 \%$ PG, $4 \%$ hydroxypropyl- $\beta$-cyclodextrin (HBC) in $10 \%$ glucose/water as the vehicle group, and $25 \mathrm{mg} / \mathrm{kg} 25 \mathrm{HC} 3 \mathrm{~S}$ in vehicle for the $25 \mathrm{HC} 3 \mathrm{~S}$ group. The mice were sacrificed at $24 \mathrm{~h}$ following the treatment. Total DNA were extracted from $25 \mathrm{mg}$ of liver tissues, and $5.2 \mu \mathrm{g}$ of the extracted DNA were used to create the whole genome bisulfite sequencing libraries. (A) Venn diagrams of hypomethylated DMR-associated genes (DMGs) in 25HC3S and vehicle libraries under CG, CHG, and CHH contexts of whole genome (Up) and promoter regions (Low). KOBAS software was used to test the statistical enrichment of DMR related genes in the Kyoto Encyclopedia of Genes and Genomes (KEGG) pathways. (B) High enrichment of hypomethylated DMRs in promoter regions in KEGG pathways. The detailed KEGG pathways as shown in Supplemental Table S3. (C) Represents the gene expression, mRNA levels of demethylated genes involved in PI3K-Akt signaling pathway; and (D) MAPK signaling pathway.

Table 2. Methylation of DMR in gene promoter regions of MAPK signaling pathway.

\begin{tabular}{cccccccc}
\hline \multirow{2}{*}{ Gene Name } & \multirow{2}{*}{ Gene Accession ID } & \multicolumn{3}{c}{ DMR Location in Promoter Region } & \multicolumn{3}{c}{ DMR (Methylation \%) } \\
\cline { 3 - 7 } & & Chromosome & Start & End & Vehicle & 25HC3S & 25HC3S-Vehicle \\
\hline Fgf11 & NM_010198 & Chr11 & $69,802,413$ & $6,9802,474$ & 55.0 & 22.6 & -32.4 \\
Map3k6 & NM_016693 & Chr9 & $133,000,000$ & $133,000,000$ & 57.4 & 25.3 & -32.1 \\
Mapk1 & NM_001038663 & Chr10 & $16,983,558$ & $16,983,663$ & 11.5 & 4.8 & -6.7 \\
Pdgfa & NM_008808 & Chr16 & $139,000,000$ & $139,000,000$ & 28.2 & 5.3 & -22.9 \\
Pdgfb & NM_011057 & Chr5 & $80,013,952$ & $80,014,060$ & 37.0 & 6.9 & -30.1 \\
Tgfbr1 & NM_009370 & Chr15 & $47,353,529$ & $47,353,605$ & 45.8 & 8.2 & -37.6 \\
Map4k4 & NM_001252200 & Chr12 & $39,900,963$ & $39,901,013$ & 28.7 & 5.7 & -23.0 \\
Ppm1a & NM_008910 & Chr4 & $72,761,171$ & $72,761,247$ & 27.2 & 5.6 & -21.6 \\
\hline
\end{tabular}




\subsection{Relationship between ${ }^{5 m} \mathrm{C} p \mathrm{G}$ Demethylation in Promoter Regions and Gene Expression}

The relationship between gene expression and CpG methylation/demethylation have been well documented. To examine the gene expression as the function of hypomethylation in the promoter regions, genes Fgf11, Pdgfa, Pdgfb, Map3k6, Map4k4, Ywhaz, Tgfbr, Tlr4, $P i k 3 c b$, and Mapk1 in the MAPK and PI3K-Akt pathways were confirmed by RT-PCR analysis. As expected, 25HC3S treatment increased expression of $P d g f b$ by 6.8 -fold, Map3k6 1.2-fold, Map4k4 1.9-fold, Tgfbr1 4.2-fold, Tlr4 2.2-fold, Pik3cb 2.3-fold, Fgf11 1.5-fold, Ywhaz 1.3-fold, Pdgfa 1.3-fold, and Mapk1 2.6-fold. Compared with vehicle group, the expression of genes involved in PI3K-Akt (Figure 4C) and MAPK (Figure 4D) signaling pathways were significantly increased in the $25 \mathrm{HC} 3 \mathrm{~S}$ treated group $(p<0.05)$.

\subsection{HC3S Stabilize the Mitochondrial Polarization}

Mitochondrial depolarization and leakage resulting from the mitochondrial permeability transition (MPT) is a key step for necrosis and apoptosis [41]. The MPT blockers, such as cyclosporine A, prevent the loss of the mitochondrial membrane potential and onset of cell death. It has been hypothesized that MPT is a causative mechanism of acute necrotic cell death [42].

Mitochondrial dysfunction, including loss of mitochondrial membrane potential (MMP), has been proposed as the main sub cellular mechanism in hepatotoxicity induced by APAP overdose [6]. In order to assess the effect of $25 \mathrm{HC} 3 \mathrm{~S}$ on MMP of hepatocytes, Huh-7 cells were treated as indicated in the Methods section. Consistent with the in vivo data, 25HC3S prevented loss of MMP, as shown by JC-1 assay (Figure 5A). APAP treatment resulted in loss of MMP by 30\% (compared to normal cell), both PG and 25HC3S+PG minimized loss of MMP dose-dependently with 25HC3S+PG showing better protective activity.
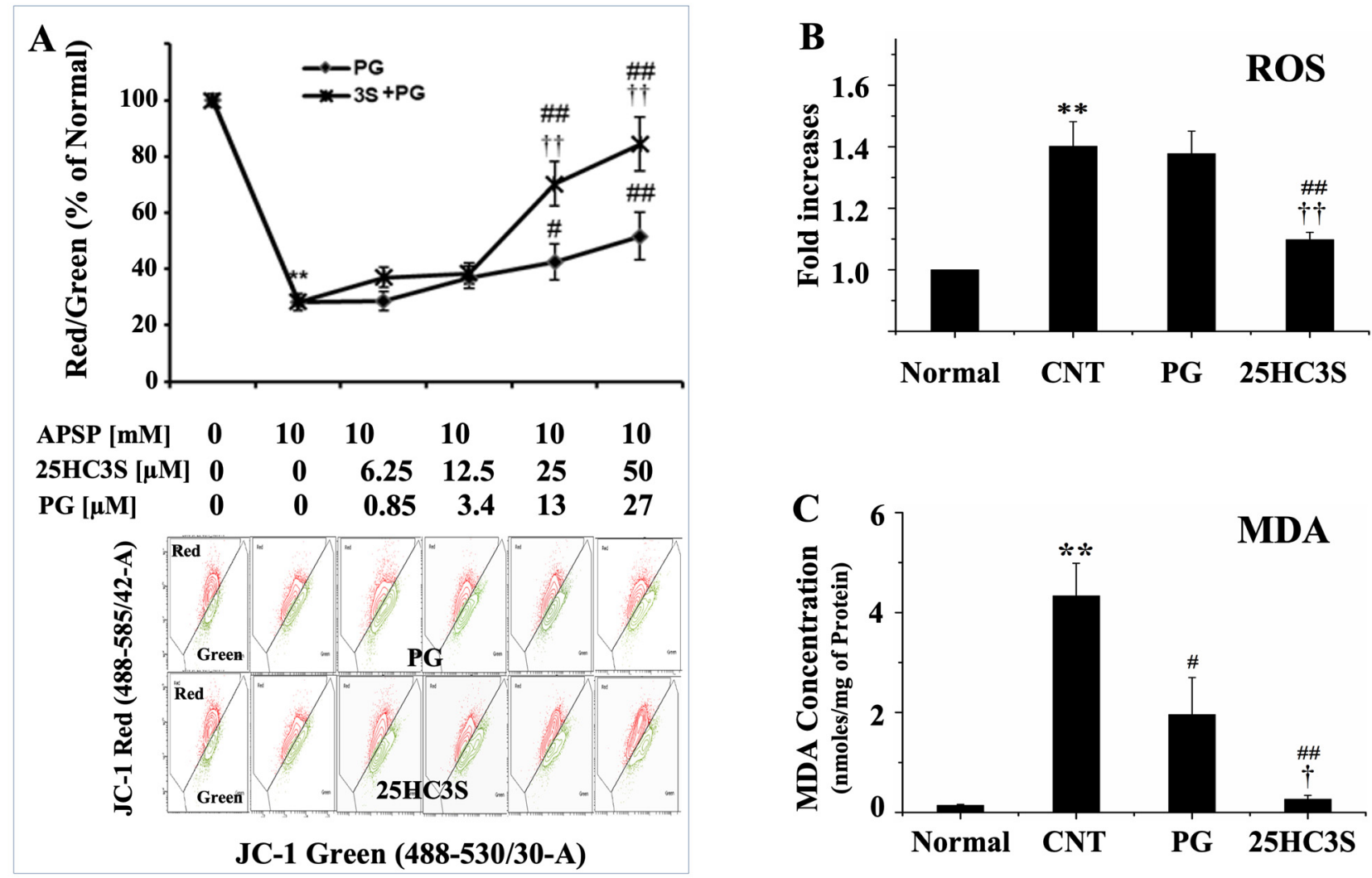

Figure 5. 25HC3S restores the injured mitochondria membrane potential and decreases oxidant levels. (A) shows effects of 25HC3S on mitochondrial polarization, Huh-7 cells were seeded in $60 \mathrm{~mm}$ dishes at $6.5 \times 10^{5} /$ dish and cultured overnight before different dosages of 25HC3S $(6.25,12.5,25,50 \mu \mathrm{M}$ in PG) were added, the relative amount PG were added as control $(0.85,3.4,13$, and $27 \mu \mathrm{M})$. Two hours later, cells were treated with $10 \mathrm{mM}$ APAP for $24 \mathrm{~h}$ and harvested. Cells without any 
treatment were used as control. MMP was analyzed by JC-1 staining on flow cytometer using $488 \mathrm{~nm}$ excitation with $530 / 30 \mathrm{~nm}$ (Green) and 585/42 nm (Red) band-pass emission filters. MMP was indicated by red/green fluorescence ratio. (B) shows 25HC3S significantly decreases ROS levels in Huh-7 cells. Huh-7 cells were pretreated with the $50 \mu \mathrm{M} 25 \mathrm{HC} 3 \mathrm{~S}$ and/or vehicle for $2 \mathrm{~h}$ before $10 \mathrm{mM}$ APAP was added. Sixteen hours after APAP addition, the cells were harvested. H2DCFDA method was used to detect ROS levels by flow cytometry. Results were expressed as the relative changes compared to untreated cells. (C) shows MDA levels in liver tissues. Mice were challenged with $350 \mathrm{mg} / \mathrm{kg}$ APAP for $30 \mathrm{~min}$ and treated with $25 \mathrm{mg} / \mathrm{kg} 25 \mathrm{HC} 3 \mathrm{~S}$ for $24 \mathrm{~h}$. The liver tissues were harvested and $100 \mathrm{mg}$ was homogenized. MDA were extracted and determined by the bicinchoninic acid assay kit purchased from Pierce (Rockford, IL, USA). The amount of lipid peroxidation, MDA, was expressed as nmol/mg protein. Data represent the mean \pm SD for three independent experiments. The symbol ${ }^{* *}$ indicates $p<0.01$ versus Normal group; \# indicates $p<0.05$ and \#\# indicates $p<0.01$ versus CNT group and ++ indicates $p<0.01$ versus PG group.

The production and release of ROS (reactive oxygen species) from damaged mitochondria are critical in oxidative damage in pathogenesis and contribute to retrograde redox signaling from the organelle to the cytosol and nucleus $[43,44]$. ROS degrades polyunsaturated lipids, forming malondialdehyde (MDA) [45]. MDA is a highly reactive compound that occurs as an enol form [46]. It occurs naturally and is a marker for oxidative stress. To confirm the effect of 25HC3S on mitochondrial polarization, the levels of ROS and MDA in liver tissues were determined. As expected, APAP overdose significantly increased ROS by $40 \%$ and MDA by 30 -fold. $25 \mathrm{HC} 3 \mathrm{~S}$ treatment restored the levels of both to the normal as shown in Figure 5B,C with a slight increase of GSH levels (data not shown). The results demonstrate that $25 \mathrm{HC} 3 \mathrm{~S}$ decreased ROS and MDA by maintaining the polarization of the mitochondrial membrane and integrity of the important cellular organelle.

\section{Discussion}

This study helped to elucidate the mechanisms by which 25HC3S recovered APAP induced acute multiple organ injury, including lung, kidney, and especially the liver, and decreased mortality in mouse models. 25HC3S has been shown to be an endogenous DNMT inhibitor and the key regulator in gene regulation [18]. The data from the present study showed that $25 \mathrm{HC} 3 \mathrm{~S}$ stabilized mitochondrial polarization, decreased the levels of intracellular oxidants, and promoted recovery of hepatic function via DNA ${ }^{5 \mathrm{~m}} \mathrm{CpG}$ demethylation in promoter regions of genes involved in important PI3K-Akt and MAPK signaling pathways. These results, based on large data analysis from both in vitro and a well-studied animal model of APAP overdose, present the mechanism by which $25 \mathrm{HC} 3 \mathrm{~S}$ regulates critical cell signaling pathways to prevent acute organ injury.

The present results also provide strong evidence that the combination of $25 \mathrm{HC} 3 \mathrm{~S}+\mathrm{NAC}$ in PG solution may have synergistic effects on the recovery of APAP induced acute organ injury as shown in Figure 6A, especially the liver injury. NAC is a potent reducing agent and at high concentrations is able to increase GSH, which neutralizes the toxic metabolite NAPQI. NAPQI causes cell death via depolarization of mitochondria. NAC increases glutathione regeneration and enhances the detoxification metabolic pathway of APAP [47]. NAC is the current standard of care for APAP overdose [48]. However, the therapeutic effectiveness of NAC is inversely related to the time when NAC is administered after APAP overdose [49]. NAC also presents with some concerning side effects with up to $18 \%$ of patients receiving IV NAC reported anaphylactic reactions (rash, hypotension, wheezing, and shortness of breath) [50]. Oral administration, although effective, is not preferred due to low bioavailability and adverse events, such as nausea/vomiting and unpleasant taste [51]. Therefore, new therapies for APAP overdose are needed.

PG is a compendial pharmaceutical excipient. Products containing PG have been approved by FDA for clinical use [52]. PG has been shown to inhibit generation of NAPQI via inactivation of CYP2E1 activity $[53,54]$. Inhibition of CYP2E1 was accomplished by administering a pediatric preparation of APAP containing PG, which resulted in reduced CYP2E1-derived metabolites [55]. In another clinical trial, human subjects were randomized to receive $\sim 50 \mathrm{mg} / \mathrm{kg}$ APAP daily in one arm and $50 \mathrm{mg} / \mathrm{kg}$ APAP in $5 \mathrm{~mL}$ of $99 \%$ PG 
daily in the other arm for 14 days. A $>2$-fold increase from baseline in ALT was considered as APAP responders. Although there was no difference in percentage of responders between the 2 arms, the mean percentage of CYP-derived metabolites was $5.8 \%$ (APAP) versus $4.3 \%(\mathrm{APAP}+\mathrm{PG}), p=0.018$. Among $\mathrm{APAP}$ responders, the mean percentage of $\mathrm{CYP}$ metabolites was $7.7 \%$ (APAP, $n=6$ of 21 ) versus $4.6 \%$ (APAP+PG, $n=8$ of 20), $p=0.050$, whereas there was no difference among 2 arms of non-responders. The results indicate that PG inhibits CYP2E1-derived metabolites of APAP but does not affect hepato cellular injury at the given dose $[54,55]$. In the present study, PG significantly decreased APAP induced liver injury markers, LDH, ASP and ALT, in mice, showing that it protected liver from injury from APAP overdose. However, PG did not seem to prevent the activation of cell death pathways.

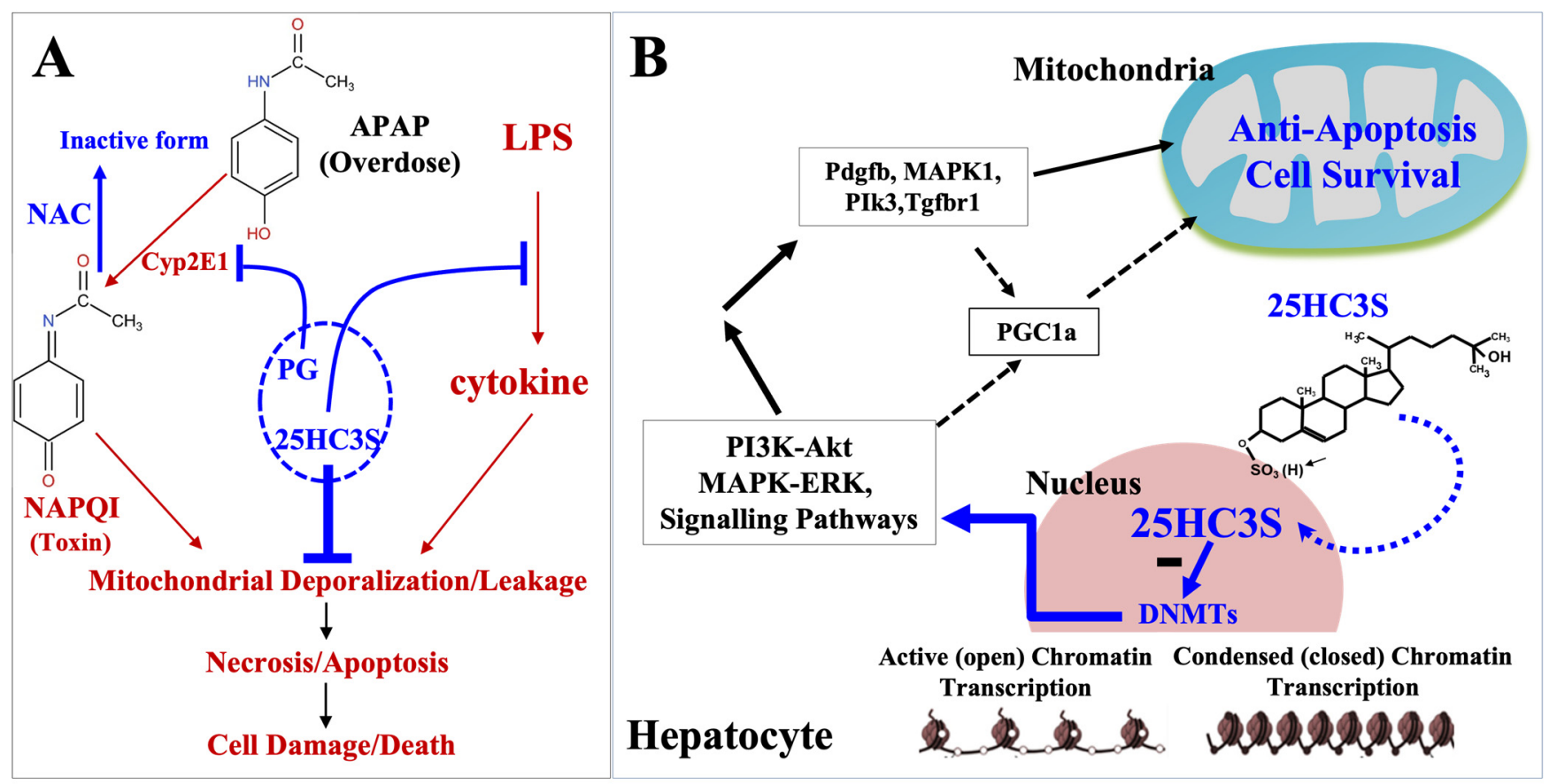

Figure 6. Schematic diagram depicting pharmaceutical mechanism. PG suppresses generation of NAPQI by inhibiting Cyp2E1 activity [55]. NAC is to promote hepatic glutathione (GSH) synthesis, which supports the detoxification of NAPQI and reduces protein binding [47,56,57]. The synergic effect of 25HC3S with NAC and PG on cell anti-apoptosis and cell survivals is shown in Panel (A). When 25HC3S enters to nuclear and potently inhibits DNMT-1, and 3a/3b, resulting in demethylation of ${ }^{5 \mathrm{~m}} \mathrm{CpG}$ in promoter regions of key genes involved in PI3K and MAPK signaling pathways. The increases in the expression of these key genes, Fgf11, Pdgfa, Pdgfb, Map3k6, Map4k4, Ywhaz, Tgfbr, Tlr4, Pik3cb, and Mapk1 in the MAPK and PI3K-Akt pathways lead to mitochondrial stabilization and polarization, and subsequently decreases levels of oxidants, ROS and MDA, resulting in cell survival. Effects of combination of 25HC3S with N-acetyl cysteine (NAC) in propylene glycol (PG) on generation and neutralization of toxic APAP metabolite, NAPQI (B); and their role in maintenance of mitochondrial integrity and cell survival (anti-cell death). Solid bar represents that the data have been presented in the text, and dot bar, data have been published. Arrow represents activating, and bar, blocking.

A recent publication demonstrates a detailed molecular mechanism by which $25 \mathrm{HC} 3 \mathrm{~S}$ functions as an endogenous epigenetic regulator [30]. The enzyme kinetic study demonstrated that 25HC3S specifically inhibited DNA methyltransferases, DNMT1, DNMT3a, and DNMT3b with $\mathrm{IC}_{50}$ at $\mathrm{uM}$ levels. In human hepatocytes, high glucose (HG) induces lipid accumulation by increasing promoter CpG methylation of key genes involved in the development of non-alcoholic fatty liver diseases (NAFLD) [18]. Using this model, whole genome bisulfate sequencing (WGBS) analysis demonstrated that 25HC3S converts HG-induced ${ }^{5 \mathrm{~m}} \mathrm{CpG}$ to $\mathrm{CpG}$ in the promoter regions of more than one thousand genes. Subsequently, 25HC3S increased expression of the demethylated genes, which are involved 
in the master signaling pathways, including MAPK-ERK, calcium-AMPK, and type II diabetes mellitus pathways. Messenger RNA array analysis showed that the upregulated genes encoded for key elements of cell survival [30]. The present study shows that 25HC3S protected organ function and reduced mortality via retaining mitochondrial polarization. The combination of 25HC3S, NAC and PG provided an optimal beneficial effect in APAP overdosed mice. Combined with the published results, a novel mechanism of the combination for effective therapy of APAP-induced ALF is proposed as shown in Figure 6. In this regard, PG inhibits the production of toxic metabolite, NAPQI; NAC increases the production of GSH that neutralizes the oxidants, including NAPQI; and 25HC3S stabilizes mitochondria, blocks cell death, and promotes cell survival by up-regulating important signaling pathways. 25HC3S has also been evaluated in vitro (cells) and other in vivo animal models, including NAFLD, NASH, hepatectomy, and acute multiple organ injury [25,29]. As an investigative drug, DUR-928 (25HC3S) has been in clinical trials in patients with NASH and acute alcohol-associated hepatitis [58-61]. Results from this study suggest that 25HC3S in PG and its appropriate combination have the potential in preventing or treating certain acute organ injuries.

\section{Conclusions}

25HC3S in PG and the combination with NAC in PG have the potential to serve as an effective biomedicine in the therapy of APAP-induced acute multiple organ injury.

\section{Patents}

Ren, S., Theeuwes, F., Brown, J.F. and Lin, W. Uses of oxygenated cholesterol sulfates (OCS). International Application: PCT/US2014/072128; U.S. Patent: 10,206,883, 10,786,517, 29 September 2020; Austria, 2014369916; Brazil, BR112016014611-5; Canada, 2932300; China, 201480070815.5; Europe, 14874617.5-1453, 19214560.5-1112; Israel, N/A; India, 201617019059; Japan, 2016-542662; South Korea, N/A; Mexico, MX/a/2016/008495; Taiwan, 103145013.

Supplementary Materials: The following are available online at https:/ / www.mdpi.com/article / 10.3390/cells10113027/s1, Table S1: Primer Sequence for Real-time Polymerase Chain Reaction, Table S2: Summary of The Whole Genome Bisulfite Sequencing Data, Table S3: Significant Enrichment KEGG Pathways of hypomethylated DMGs in Promoter Region under CG context.

Author Contributions: Y.W. designed and conducted the experiments and wrote the paper; S.R. designed experiments, wrote the paper, and PI of the project; W.M.P., E.J.L. and P.B.H. gave a suggestion and edited the manuscript. All authors have read and agreed to the published version of the manuscript.

Funding: This project has been supported by Merit Review Grant, Department of Veterans Affairs and Research Agreement, Durect Corporation, Cupertino, CA, USA.

Institutional Review Board Statement: Animal studies were approved by the Institutional Animal Care and Use Committee of McGuire Veterans Affairs Medical Center and were conducted in accordance with the Declaration of Helsinki, the Guide for the Care and Use of Laboratory Animals, and all applicable regulations.

Informed Consent Statement: Not applicable.

Data Availability Statement: All data described are contained within the article.

Acknowledgments: We appreciate James Brown and WeiQi Lin (DURECT Corporation), Yanxia Ning, Jin Koung Kim, and Roy Wang for their contribution to this manuscript.

Conflicts of Interest: S.R. and Virginia Commonwealth University obtain license-related payments from DURECT Corporation, Cupertino, CA, USA. 


\section{References}

1. Rajaram, P.; Subramanian, R. Acute Liver Failure. Semin. Respir. Crit. Care Med. 2018, 39, 513-522. [CrossRef]

2. Squires, J.E.; McKiernan, P.; Squires, R.H. Acute Liver Failure: An Update. Clin. Liver Dis. 2018, 22, 773-805. [CrossRef]

3. Bantel, H.; Schulze-Osthoff, K. Mechanisms of cell death in acute liver failure. Front. Physiol. 2012, 3, 79. [CrossRef]

4. Lee, W.M. Acetaminophen (APAP) hepatotoxicity-Isn't it time for APAP to go away? J. Hepatol. 2017, 67, 1324-1331. [CrossRef]

5. Margan Koletic, Z.; Dosenovic, S.; Puljak, L. Efficacy and safety of modified-release paracetamol for acute and chronic pain: A systematic review protocol. BMJ Open 2019, 9, e029728.

6. Hinson, J.A.; Roberts, D.W.; James, L.P. Mechanisms of acetaminophen-induced liver necrosis. Handb. Exp. Pharmacol. 2010, 196, 369-405.

7. Lee, W.M. Acetaminophen Toxicity: A History of Serendipity and Unintended Consequences. Clin. Liver Dis. 2020, 16 (Suppl. S1), 34-44. [CrossRef]

8. Mazaleuskaya, L.L.; Sangkuhl, K.; Thorn, C.F.; FitzGerald, G.A.; Altman, R.B.; Klein, T.E. PharmGKB summary: Pathways of acetaminophen metabolism at the therapeutic versus toxic doses. Pharm. Genom. 2015, 25, 416-426. [CrossRef]

9. McGill, M.R.; Jaeschke, H. Metabolism and disposition of acetaminophen: Recent advances in relation to hepatotoxicity and diagnosis. Pharm. Res. 2013, 30, 2174-2187. [CrossRef]

10. Hazai, E.; Vereczkey, L.; Monostory, K. Reduction of toxic metabolite formation of acetaminophen. Biochem. Biophys. Res. Commun. 2002, 291, 1089-1094. [CrossRef]

11. Ben-Shachar, R.; Chen, Y.; Luo, S.; Hartman, C.; Reed, M.; Nijhout, H.F. The biochemistry of acetaminophen hepatotoxicity and rescue: A mathematical model. Theor. Biol. Med. Model. 2012, 9, 55. [CrossRef] [PubMed]

12. Gelotte, C.K.; Auiler, J.F.; Lynch, J.M.; Temple, A.R.; Slattery, J.T. Disposition of acetaminophen at 4, 6, and $8 \mathrm{~g} /$ day for 3 days in healthy young adults. Clin. Pharm. Ther. 2007, 81, 840-848. [CrossRef]

13. Webster, K.A. Mitochondrial membrane permeabilization and cell death during myocardial infarction: Roles of calcium and reactive oxygen species. Future Cardiol. 2012, 8, 863-884. [CrossRef]

14. Zorov, D.B.; Juhaszova, M.; Sollott, S.J. Mitochondrial reactive oxygen species (ROS) and ROS-induced ROS release. Physiol. Rev. 2014, 94, 909-950. [CrossRef]

15. Redza-Dutordoir, M.; Averill-Bates, D.A. Activation of apoptosis signalling pathways by reactive oxygen species. Biochim Biophys. Acta 2016, 1863, 2977-2992. [CrossRef] [PubMed]

16. Zmysłowski, A.; Szterk, A. Oxysterols as a biomarker in diseases. Clin. Chim. Acta 2019, 491, 103-113. [CrossRef] [PubMed]

17. Willinger, T. Oxysterols in intestinal immunity and inflammation. J. Int. Med. 2019, 285, 367-380. [CrossRef] [PubMed]

18. Wang, Y.; Li, X.; Ren, S. Cholesterol Metabolites 25-Hydroxycholesterol and 25-Hydroxycholesterol 3-Sulfate Are Potent Paired Regulators: From Discovery to Clinical Usage. Metabolites 2021, 11, 9. [CrossRef]

19. Li, X.; Pandak, W.M.; Erickson, S.K.; Ma, Y.; Yin, L.; Hylemon, P.; Ren, S. Biosynthesis of the regulatory oxysterol, 5-cholesten3beta,25-diol 3-sulfate, in hepatocytes. J. Lipid Res. 2007, 48, 2587-2596. [CrossRef]

20. Bai, Q.; Zhang, X.; Xu, L.; Kakiyama, G.; Heuman, D.; Sanyal, A.; Pandak, W.M.; Yin, L.; Xie, W.; Ren, S. Oxysterol sulfation by cytosolic sulfotransferase suppresses liver $\mathrm{X}$ receptor/sterol regulatory element binding protein-1c signaling pathway and reduces serum and hepatic lipids in mouse models of nonalcoholic fatty liver disease. Metabolism 2012, 61, 836-845. [CrossRef]

21. Ma, Y.; Xu, L.; Rodriguez-Agudo, D.; Li, X.; Heuman, D.M.; Hylemon, P.B.; Pandak, W.M.; Ren, S. 25-Hydroxycholesterol-3-sulfate regulates macrophage lipid metabolism via the LXR/SREBP-1 signaling pathway. Am. J. Physiol. Endocrinol. Metab. 2008, 295, E1369-E1379. [CrossRef] [PubMed]

22. Ren, S.; Li, X.; Rodriguez-Agudo, D.; Gil, G.; Hylemon, P.; Pandak, W.M. Sulfated oxysterol, 25HC3S, is a potent regulator of lipid metabolism in human hepatocytes. Biochem. Biophys. Res. Commun. 2007, 360, 802-808. [CrossRef] [PubMed]

23. Ren, S.; Ning, Y. Sulfation of 25-hydroxycholesterol regulates lipid metabolism, inflammatory responses, and cell proliferation. Am. J. Physiol. Endocrinol. Metab. 2014, 306, E123-E130. [CrossRef]

24. Xu, L.; Bai, Q.; Rodriguez-Agudo, D.; Hylemon, P.B.; Heuman, D.M.; Pandak, W.M.; Ren, S. Regulation of hepatocyte lipid metabolism and inflammatory response by 25-hydroxycholesterol and 25-hydroxycholesterol-3-sulfate. Lipids 2010, 45, 821-832. [CrossRef]

25. Xu, L.; Kim, J.K.; Bai, Q.; Zhang, X.; Kakiyama, G.; Min, H.K.; Sanyal, A.J.; Pandak, W.M.; Ren, S. 5-cholesten-3 $\beta$,25-diol 3-sulfate decreases lipid accumulation in diet-induced nonalcoholic fatty liver disease mouse model. Mol. Pharm. 2013, 83, 648-658. [CrossRef] [PubMed]

26. Xu, L.; Shen, S.; Ma, Y.; Kim, J.K.; Rodriguez-Agudo, D.; Heuman, D.M.; Hylemon, P.B.; Pandak, W.M.; Ren, S. 25Hydroxycholesterol-3-sulfate attenuates inflammatory response via PPAR $\gamma$ signaling in human THP-1 macrophages. Am. J. Physiol. Endocrinol. Metab. 2012, 302, E788-E799. [CrossRef] [PubMed]

27. Zhang, X.; Bai, Q.; Kakiyama, G.; Xu, L.; Kim, J.K.; Pandak, W.M., Jr.; Ren, S. Cholesterol metabolite, 5-cholesten-3ß-25-diol-3sulfate, promotes hepatic proliferation in mice. J. Steroid Biochem. Mol. Biol. 2012, 132, 262-270. [CrossRef]

28. Zhang, X.; Bai, Q.; Xu, L.; Kakiyama, G.; Pandak, W.M., Jr.; Zhang, Z.; Ren, S. Cytosolic sulfotransferase 2B1b promotes hepatocyte proliferation gene expression in vivo and in vitro. Am. J. Physiol. Gastrointest. Liver Physiol. 2012, 303, G344-G355. [CrossRef]

29. Ning, Y.; Kim, J.K.; Min, H.K.; Ren, S. Cholesterol metabolites alleviate injured liver function and decrease mortality in an LPS-induced mouse model. Metabolism 2017, 71, 83-93. [CrossRef] 
30. Wang, Y.; Lin, W.; Brown, J.E.; Chen, L.; Pandak, W.M.; Hylemon, P.B.; Ren, S. 25-Hydroxycholesterol 3-sulfate is an endogenous ligand of DNA methyltransferases in hepatocytes. J. Lipid Res. 2021, 62, 100063. [CrossRef]

31. Yang, R.; Zou, X.; Koskinen, M.L.; Tenhunen, J. Ethyl pyruvate reduces liver injury at early phase but impairs regeneration at late phase in acetaminophen overdose. Crit. Care 2012, 16, R9. [CrossRef]

32. Lalazar, G.; Ilyas, G.; Malik, S.A.; Liu, K.; Zhao, E.; Amir, M.; Lin, Y.; Tanaka, K.E.; Czaja, M.J. Autophagy confers resistance to lipopolysaccharide-induced mouse hepatocyte injury. Am. J. Physiol. Gastrointest. Liver Physiol. 2016, 311, G377-G386. [CrossRef] [PubMed]

33. Wang, Y.; Chen, L.; Pandak, W.M.; Heuman, D.; Hylemon, P.B.; Ren, S. High Glucose Induces Lipid Accumulation via 25Hydroxycholesterol DNA-CpG Methylation. iScience 2020, 23, 101102. [CrossRef]

34. Xie, Y.; McGill, M.R.; Dorko, K.; Kumer, S.C.; Schmitt, T.M.; Forster, J.; Jaeschke, H. Mechanisms of acetaminophen-induced cell death in primary human hepatocytes. Toxicol. Appl. Pharmacol. 2014, 279, 266-274. [CrossRef] [PubMed]

35. Dikalov, S.I.; Harrison, D.G. Methods for detection of mitochondrial and cellular reactive oxygen species. Antioxid Redox Signal. 2014, 20, 372-382. [CrossRef] [PubMed]

36. Ohkawa, H.; Ohishi, N.; Yagi, K. Assay for lipid peroxides in animal tissues by thiobarbituric acid reaction. Anal. Biochem. 1979, 95, 351-358. [CrossRef]

37. Mihara, M.; Uchiyama, M. Determination of malonaldehyde precursor in tissues by thiobarbituric acid test. Anal. Biochem. 1978, $86,271-278$

38. Hodgman, M.J.; Garrard, A.R. A review of acetaminophen poisoning. Crit. Care Clin. 2012, 28, 499-516. [CrossRef]

39. Alvarenga, D.M.; Mattos, M.S.; Lopes, M.E.; Marchesi, S.C.; Araújo, A.M.; Nakagaki, B.N.; Santos, M.M.; David, B.A.; De Souza, V.A.; Carvalho, É.; et al. Paradoxical Role of Matrix Metalloproteinases in Liver Injury and Regeneration after Sterile Acute Hepatic Failure. Cells 2018, 7, 247. [CrossRef]

40. Monti-Rocha, R.; Cramer, A.; Gaio Leite, P.; Antunes, M.M.; Pereira, R.V.S.; Barroso, A.; Queiroz-Junior, C.M.; David, B.A.; Teixeira, M.M.; Menezes, G.B.; et al. SOCS2 Is Critical for the Balancing of Immune Response and Oxidate Stress Protecting Against Acetaminophen-Induced Acute Liver Injury. Front. Immunol. 2018, 9, 3134. [CrossRef]

41. Lemasters, J.J.; Nieminen, A.L.; Qian, T.; Trost, L.C.; Elmore, S.P.; Nishimura, Y.; Crowe, R.A.; Cascio, W.E.; Bradham, C.A.; Brenner, D.A.; et al. The mitochondrial permeability transition in cell death: A common mechanism in necrosis, apoptosis and autophagy. Biochim. Biophys. Acta 1998, 136, 177-196. [CrossRef]

42. Lemasters, J.J.; Theruvath, T.P.; Zhong, Z.; Nieminen, A.L. Mitochondrial calcium and the permeability transition in cell death. Biochim. Biophy. Acta 2009, 1787, 1395-1401. [CrossRef] [PubMed]

43. Murphy, M.P. How mitochondria produce reactive oxygen species. Biochem. J. 2009, 417, 1-13. [CrossRef]

44. Chen, Y.; Zhou, Z.; Min, W. Mitochondria, Oxidative Stress and Innate Immunity. Front. Physiol. 2018, 9, 1487. [CrossRef]

45. Gaschler, M.M.; Stockwell, B.R. Lipid peroxidation in cell death. Biochem. Biophys. Res. Commun. 2017, 482, 419-425. [CrossRef]

46. Ayala, A.; Muñoz, M.F.; Argüelles, S. Lipid peroxidation: Production, metabolism, and signaling mechanisms of malondialdehyde and 4-hydroxy-2-nonenal. Oxid Med. Cell. Longev. 2014, 2014, 360438. [CrossRef] [PubMed]

47. Saito, C.; Zwingmann, C.; Jaeschke, H. Novel mechanisms of protection against acetaminophen hepatotoxicity in mice by glutathione and N-acetylcysteine. Hepatology 2010, 51, 246-254. [CrossRef]

48. Heard, K.J. Acetylcysteine for acetaminophen poisoning. N. Engl. J. Med. 2008, 359, 285-292. [CrossRef] [PubMed]

49. Hendrickson, R.G. What is the most appropriate dose of N-acetylcysteine after massive acetaminophen overdose? Clin. Toxicol. 2019, 57, 686-691. [CrossRef]

50. Yarema, M.; Chopra, P.; Sivilotti, M.L.A.; Johnson, D.; Nettel-Aguirre, A.; Bailey, B.; Victorino, C.; Gosselin, S.; Purssell, R.; Thompson, M.; et al. Anaphylactoid Reactions to Intravenous N-Acetylcysteine during Treatment for Acetaminophen Poisoning J. Med. Toxicol. 2018, 14, 120-127. [CrossRef]

51. Lyu, X.; Zhao, C.; Yan, Z.M.; Hua, H. Efficacy of nystatin for the treatment of oral candidiasis: A systematic review and meta-analysis. Drug Des. Dev. Ther. 2016, 10, 1161-1171. [CrossRef] [PubMed]

52. Jacob, S.E.; Scheman, A.; McGowan, M.A. Propylene Glycol. Dermatitis 2018, 29, 3-5. [CrossRef] [PubMed]

53. Thomsen, M.S.; Loft, S.; Roberts, D.W.; Poulsen, H.E. Cytochrome P4502E1 inhibition by propylene glycol prevents acetaminophen (paracetamol) hepatotoxicity in mice without cytochrome P4501A2 inhibition. Pharm. Toxicol. 1995, 76, 395-399. [CrossRef] [PubMed]

54. Zhao, P.; Kalhorn, T.F.; Slattery, J.T. Selective mitochondrial glutathione depletion by ethanol enhances acetaminophen toxicity in rat liver. Hepatology 2002, 36, 326-335. [CrossRef] [PubMed]

55. Ganetsky, M.; Berg, A.H.; Solano, J.J.; Salhanick, S. Inhibition of CYP2E1 With Propylene Glycol Does Not Protect Against Hepatocellular Injury in Human Acetaminophen Daily-Dosing Model. J. Clin. Pharmacol. 2019, 59, 131-138. [CrossRef] [PubMed]

56. Lauterburg, B.H.; Corcoran, G.B.; Mitchell, J.R. Mechanism of action of N-acetylcysteine in the protection against the hepatotoxicity of acetaminophen in rats in vivo. J. Clin. Investig. 1983, 71, 980-991. [CrossRef] [PubMed]

57. Corcoran, G.B.; Wong, B.K. Role of glutathione in prevention of acetaminophen-induced hepatotoxicity by N-acetyl-L-cysteine in vivo: Studies with N-acetyl-D-cysteine in mice. J. Pharmacol. Exp. Ther. 1986, 238, 54-61.

58. Smith, H.S. Perioperative intravenous acetaminophen and NSAIDs. Pain Med. 2011, 12, 961-981. [CrossRef] 
59. Kemp, W.S.J.; Kim, M.J.; Ellis, D.; Brown, J.; Theeuwes, F.; Lin, W.Q. Safety and pharmacokinetics of DUR-928 in patients with non-alcoholic steatohepatitis-A Phase $1 \mathrm{~b}$ study. In Proceedings of the Poster Session Presented at the International Liver Congress, Amsterdam, The Netherlands, 19-23 April 2017.

60. Shah, J.; Blevins, C.; Scott, D.; Lin, W. Pharmacokinetics of DUR-928 in Alcoholic Hepatitis Patients-A Phase 2a Study. J. Hepatol. 2020, 73, S180-S181. [CrossRef]

61. Hassanein, T. Safety and efficacy of DUR-928: A potential new therapy for acute alcoholic hepatitis. In Proceedings of the AASLD The Liver Meeting ${ }^{\circledR}$, Boston, MA, USA, 12 November 2019. 